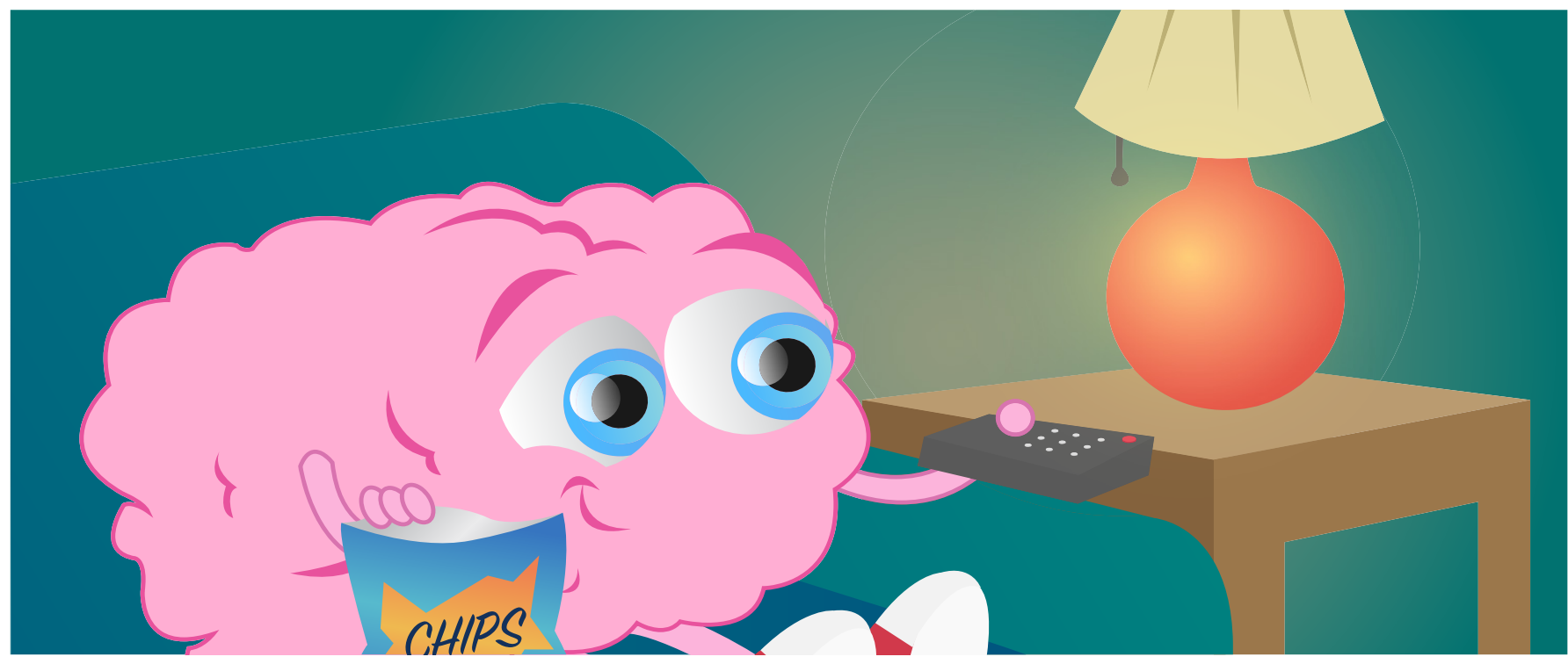

\title{
GET OFF THE COUCH! EXERCISE YOUR WAY TO A HEALTHY BRAIN
}

\section{Lindsay S. Nagamatsu*}

Exercise, Mobility, and Brain Health Lab, School of Kinesiology, Western University, London, ON, Canada

\section{REVIEWED BY:}

DYLAN

10 YEARS OLD
We all know that physical activity is good for the heart and lungs, but is it also good for the brain? Research has shown that regular physical activity can boost brain performance in various different kinds of people, from children and young adults to older adults at-risk of developing Alzheimer's disease. These improvements in brain performance can be measured by tests of memory, thinking, and attention. It is thought that physical activity improves brain performance by changing both the way the brain functions and its size, a process known as neuroplasticity. In particular, physical activity may increase the size of a part of the brain called the hippocampus - the brain's memory center. Importantly, the benefits of physical activity on the brain are seen at all ages, which means it is never too late to start exercising to help the brain. This research shows that being physically active may be an enjoyable way to help you improve your grades at school now and to keep your brain healthy throughout your life.

\section{PHYSICAL ACTIVITY IS IMPORTANT}

Physical activity includes any activity that gets the body moving and the heart pumping - from walking and running to swimming, playing soccer, or 
COGNITIVE

\section{FUNCTION}

The way we process and think about the world around us. Cognitive functions include attention, memory, and ability to solve problems. playing tag on the playground. It is well known that physical activity is important for living a long and healthy life. People who exercise more have lower risk of many diseases that affect the body, such as heart disease.

Unfortunately, these days people in general are less active-or more "sedentary" - than ever before. This may be because of our increasing use of technology. In particular, we are spending more time indoors watching TV, playing video games, and on our computers. This means we have less time to be physically active. Our increasingly sedentary behavior has become a major problem in our society, with rates of obesity skyrocketing in recent decades, negatively impacting the health and well-being of many people. In this article, we will explore some of the reasons why physical activity may be more important for our health than we previously thought.

\section{PHYSICAL ACTIVITY IMPROVES BRAIN FUNCTION}

We all know that physical activity is good for the heart and lungs, but is it also good for the mind? In the past, researchers have observed that people who exercise more tend to have better cognitive function. Cognitive functions are processes in the brain that are responsible for the way we think and respond to the environment. Examples of cognitive functions are attention, memory, and decision-making. Research on physical activity and cognitive function has found that athletes have faster reaction times, meaning their brains work more efficiently. In addition, older adults who exercise more have better attention and decision-making abilities. However, because many different factors could affect the relationship between physical activity and cognitive function, researchers have recently studied this effect in the laboratory, where they can more easily control all experimental variables.

In one study, researchers split a group of older adults (58-77 years old) into two groups [1]. One group walked for 40-45 min three times per week for 6 months. Instead of walking, the other group did balance and stretching for the same amount of time. The researchers found that the walking group significantly improved their performance on decision-making tests after the 6-month study. This suggests that regular walking can improve cognitive functions, which will help people in their everyday lives. Similar results have also been found in children. Children who are more physically active perform better on a wide variety of tests, including those that measure creativity, concentration, IQ, mathematics skills, and verbal skills-all of which help kids do better at school and set them up for success later in life.

\section{PHYSICAL ACTIVITY CAN CHANGE THE BRAIN}

The brain is one of the most important and complex organs in the body, responsible for the way we act, feel, and think. Changes in the brain can alter behavior depending on what specific brain region is changing. Research has 
shown that physical activity can modify the functioning of multiple different areas of the brain. One area that changes in response to physical activity is the frontal lobe (Figure 1). The frontal lobe is responsible for helping us think and solve problems. Regular exercise has been shown to increase brain activity in the frontal lobe, which therefore leads to an improved ability to perform tasks that require higher level thinking. For example, in one study, participants completed the Eriksen Flanker task (Figure 2), a test that measures a person's ability to think and pay attention to the most important information. In this task, participants have to indicate the direction (left or right) that the center fish is pointing. In some of the trials, all the fish are pointing in the same direction (match). In the other trials, the center fish is pointing in the opposite direction of the rest of the fish (non-match). The non-match trials are more difficult than the match trials because you have to ignore the other fish to make the correct response. In this study, participants who exercised twice per week for 1 year significantly increased their brain activity in the frontal lobe while they performed this task [2]. Changes in the brain can be measured using magnetic resonance imaging (MRI) (Figure 3). An MRI machine is essentially a large magnet that takes pictures of the brain while participants lay still inside of it. This allows researchers to "see" what is happening inside the brain when people are doing a task.

In addition to improving attention, memory, and brain function, research has shown that physical activity also changes the size of the brain. In terms of changing brain size, physical activity has the biggest effect on an area of the brain called the hippocampus. The hippocampus is a seahorse-shaped structure located in the middle of the brain (Figure 1). It is the "memory-center" of the brain responsible for helping people form new memories. In one study [3], older adults (55-80 years old) who walked $40 \mathrm{~min} /$ day, 3 days/week, for 1 year, increased the size of their hippocampus by an average of $2 \%$.

Similar results have been found in children as well. The 9- and 10-year olds who were more fit had a larger hippocampus than those who were less fit [4]. Importantly, the larger hippocampus in the children who were more fit helped

\section{FIGURE}

Overview of important regions in the brain. The left image shows the outer surface of the brain, while the right image shows regions inside the brain. The frontal lobe and hippocampus are indicated by red boxes.

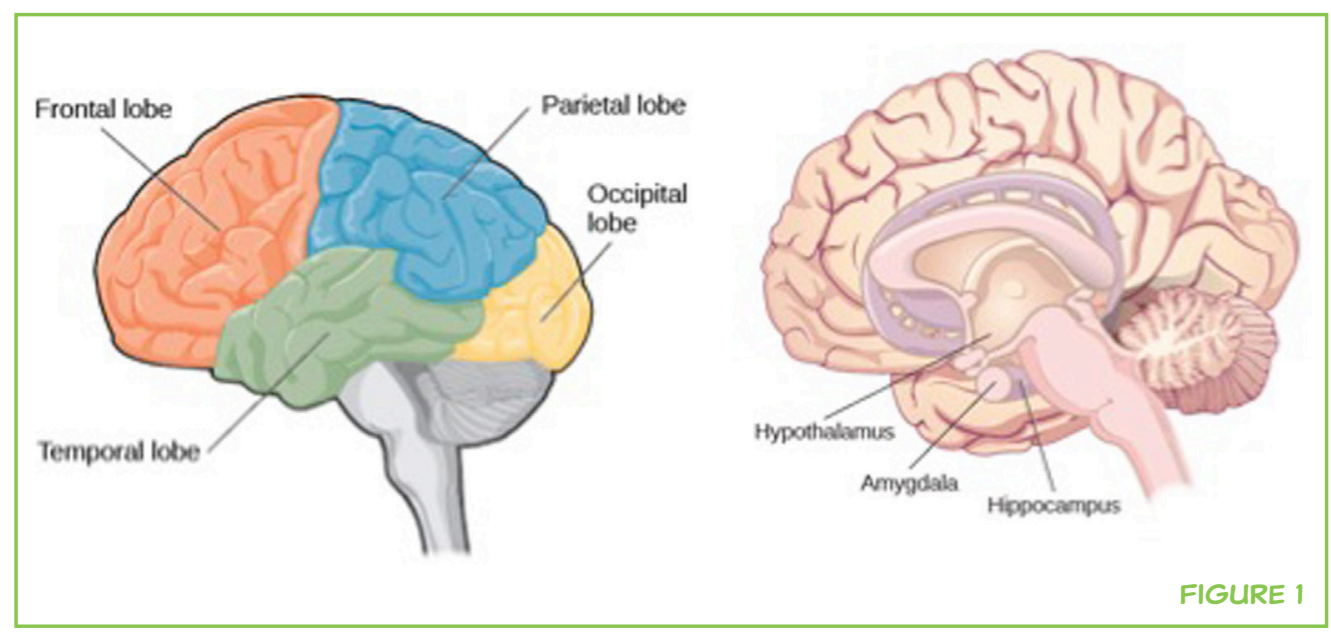


FIGURE 2

The Eriksen Flanker task.

The participant must

decide which direction the middle fish is pointing (left or right) while ignoring the other fish. Responses must be made as quickly and accurately as possible. On "match" trials, all of the fish are pointing in the same direction. On "non-match trials," the middle fish is pointing the opposite direction as the rest of the fish. Non-match trials are more difficult because a person's first instinct is to indicate the direction that most of the fish are pointing. Therefore, participants must really pay attention to respond to only the middle fish on these trials. For a demonstration, see https://youtu.be/ IXVmSqfSML4.

\section{NEUROPLAS- TICITY}

Changes that happen in the brain as the result of our experiences.

\section{ALZHEIMER'S DISEASE}

A disease that affects the brain in older age. The main characteristic of Alzheimer's disease is a problem with cognitive functions, especially memory.

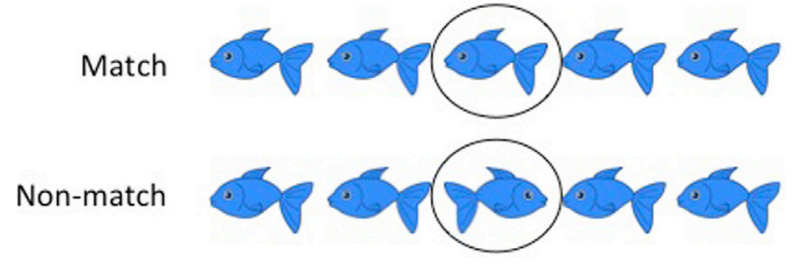

FIGURE 2

them perform better on memory tests. The process that results in changes in brain function and size is known as neuroplasticity.

\section{WHAT IS NEUROPLASTICITY?}

Neuroplasticity is the idea that the brain can change over time. This means the size of the brain can change (grow or shrink), but importantly the brain can change in other ways as well. For example, people can grow new brain cells, make existing brain cells stronger, and improve the connections between brain cells. Most of the changes that happen in the brain occur when we are very young, when the brain is growing and developing at a rapid rate. However, we now know that the brain changes across a person's entire life span. The brain changes in response to new experiences, and these changes are important for helping us learn new information and skills. This is why changes in the brain due to physical activity help people to remember things and to process information more easily.

\section{EXERCISE AND BRAIN DISEASES}

Importantly, exercise may help to ward off brain diseases in older adults, such as Alzheimer's disease. Alzheimer's disease is a disease that affects the structure and function of the brain, which results in problems doing everyday tasks. One of the first symptoms of Alzheimer's disease is difficulty in remembering recent events. Millions of older adults suffer from Alzheimer's disease worldwide. Although there is no known cure or medication that can treat Alzheimer's disease, there are lifestyle factors that can reduce the risk of getting Alzheimer's disease in the first place. One possible lifestyle factor is physical activity. Research has found that regular physical activity can improve memory, thinking, attention, and brain function and structure in older adults who have already memory problems - and therefore are at a higher risk of developing Alzheimer's disease. This research suggests that exercise may be able to prevent or delay the onset of this disease in older adults.

\section{LET'S EXERCISE!}

Based on the evidence that has been presented in this article, it is clear that physical activity has benefits to not only the body but also the mind and brain. This means that physical activity can help you in your daily lives, by helping you 
FIGURE 3

A magnetic resonance imaging machine.

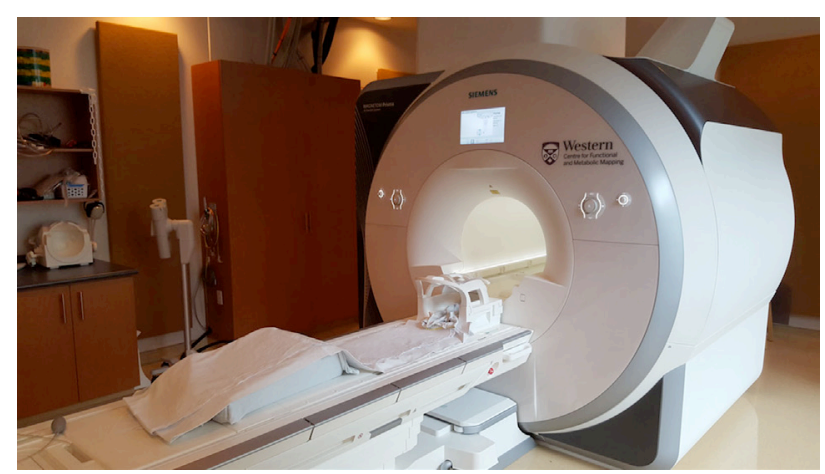

FIGURE 3

to remember to do your homework and pay better attention in class. Physical activity has the same benefits in older adults and can also help to reduce the likelihood of developing memory-related diseases, such as Alzheimer's disease. It is also important to remember that physical activity can benefit everyoneand it's never too late to start! Even older adults who already have memory problems can improve their brain function if they start exercising now.

Importantly, physical activity can improve cognitive and brain function in people of all ages. So what does that mean for us? We need to exercise more! Whether it is taking a walk with a friend or family member, playing sports, or going for a bike ride, physical activity is a great way to get the body moving while strengthening the brain as well. It is recommended that children participate in $60 \mathrm{~min}$ or more of physical activity daily. For adults and seniors, the experts recommend a minimum of $30 \mathrm{~min}$ a day, 5 days a week, of moderate-intensity physical activity, such as swimming, jogging, or biking. Physical activity is more fun when you do it with other people. So encourage your friends, siblings, parents, and grandparents-it is time to get off the couch together and get some exercise!

\section{REFERENCES}

1. Colcombe, S. J., Kramer, A. F., Erickson, K. I., Scalf, P., McAuley, E., Cohen, N. J., et al. 2004. Cardiovascular fitness, cortical plasticity, and aging. Proc. Natl. Acad. Sci. U.S.A. 101(9):3316-21. doi:10.1073/pnas.0400266101

2. Liu-Ambrose, T., Nagamatsu, L. S., Voss, M. W., Khan, K. M., and Handy, T. C. 2012. Resistance training and functional plasticity of the aging brain: a 12-month randomized controlled trial. Neurobiol. Aging 33(8):1690-8. doi:10.1016/ j.neurobiolaging.2011.05.010

3. Erickson, K. I., Voss, M. W., Prakash, R. S., Basak, C., Szabo, A., Chaddock, L., et al. 2011. Exercise training increases size of hippocampus and improves memory. Proc. Natl. Acad. Sci. U.S.A. 108(7):3017-22. doi:10.1073/pnas.1015950108

4. Chaddock, L., Erickson, K. I., Prakash, R. S., Kim, J. S., Voss, M. W., Vanpatter, M., et al. 2010. A neuroimaging investigation of the association between aerobic fitness, hippocampal volume, and memory performance in preadolescent children. Brain Res. 1358:172-83. doi:10.1016/j.brainres.2010.08.049 
SUBMITTED: 18 December 2015; ACCEPTED: 26 April 2017;

PUBLISHED ONLINE: 17 May 2017.

EDITED BY: Fulvio D’Acquisto, Queen Mary University of London, UK

CITATION: Nagamatsu LS (2017) Get Off the Couch! Exercise Your Way to a Healthy Brain. Front. Young Minds 5:20. doi:10.3389/frym.2017.00020

CONFLICT OF INTEREST STATEMENT: The author declares that the research was conducted in the absence of any commercial or financial relationships that could be construed as a potential conflict of interest.

COPYRIGHT (C) 2017 Nagamatsu. This is an open-access article distributed under the terms of the Creative Commons Attribution License (CC BY). The use, distribution or reproduction in other forums is permitted, provided the original author(s) or licensor are credited and that the original publication in this journal is cited, in accordance with accepted academic practice. No use, distribution or reproduction is permitted which does not comply with these terms.

\section{REVIEWED BY}

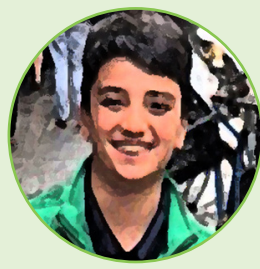

\section{DYLAN, 10 YEARS OLD}

I'm in the fourth grade and I love sports. I play soccer, baseball, and basketball. My favorite teams are the Yankees and Knicks. I like hanging out with my friends and playing Xbox. I live with my mom, dad, and younger brother, and I really want a pet dog. I like going on trips with my family.

\section{AUTHOR}

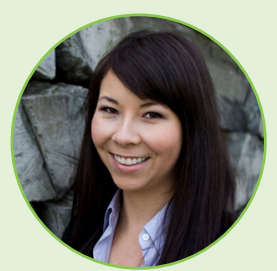

\section{LINDSAY S. NAGAMATSU}

Lindsay S. Nagamatsu is a cognitive psychologist and research scientist at Western University in Canada. She is the director of the Exercise, Mobility, and Brain Health Lab, where along with a team of graduate students, she studies how we can improve the brain function of older adults through exercise interventions. Dr. Lindsay S. Nagamatsu specializes in neuroimaging, using EEG and fMRI to examine how the brain works. In her spare time, she enjoys going to the gym, doing yoga, and taking her dog on hikes. *lindsay.nagamatsu@uwo.ca 